\title{
Connecting Community and Culture
}

\author{
Corine Meredith Brown ${ }^{1} \&$ Meg White ${ }^{2}$ \\ ${ }^{1}$ College of Education, Rowan University, Glassboro, New Jersey, USA \\ ${ }^{2}$ School of Education, The Richard Stockton College of New Jersey, Galloway, New Jersey, USA \\ Correspondence: Corine Meredith Brown, College of Education, Rowan University, 201 Mullica Hill Road, \\ Glassboro, New Jersey, USA. Tel: 1-856-256-4500 ext 3047. E-mail: meredithc@rowan.edu
}

Received: January 20, 2014

Accepted: February 14, $2014 \quad$ Online Published: February 22, 2014

doi:10.5539/jel.v3n1p134

URL: http://dx.doi.org/10.5539/jel.v3n1p134

\begin{abstract}
In order to be effective educators in the $21^{\text {st }}$ century, it is essential for teacher candidates to develop a deep understanding of the culture and contextual factors surrounding their students' lives, and the ability to apply this understanding to classroom instruction. This action research study discusses how the implementation of teaching learning community propensities with Teacher Work Sample methodology provides a unique perspective for pre-service teachers to first examine the social context of urban students, and then to consider these contextual factors with the implications for effective instructional practices.
\end{abstract}

Keywords: teacher education, urban education, culture, community, pre-service teachers

\section{Introduction/Statement of Issue}

Effective learning communities are characterized by respect for each member and are responsive to the needs of each individual. Without a firm foundation for establishing safe and culturally responsive learning environments, our future educators may be at a disadvantage in developing and delivering classroom instruction that meets the needs of urban students. Egbo (2011) suggests that how teachers construct and interpret issues of race and diversity significantly influences their interactions with students from diverse backgrounds. This, in turn, impacts student success.

In the United States, Teacher Work Sample (TWS) methodology, an approach first introduced at Western Oregon University in the 1980 s, requires teacher candidates to use information about the teaching/learning context, the developmental characteristics of diverse learners, and the knowledge about individual differences to plan, conduct, assess, and analyze instruction. The use of Teacher Work Sample methodology integrated with learning community theory presents a new opportunity for candidates to connect community and culture. This idea is further supported by the research of Egbo (2011), who concludes teacher education programs need to have a deep knowledge and understanding about race and diversity in order to fully prepare pre-service teachers. In doing so, students gain an understanding of contextual factors. For the purposes of this research, contextual factors include geographic location, socioeconomic profile, race/ethnicity demographics, and community and school population. It is essential for teacher candidates to develop a deep understanding of the culture and contextual factors surrounding their students' lives and the ability to apply this understanding to classroom instruction. To possess one without the other is insufficient for effective teaching in the 21st century.

On a larger scale, American educational organizations and policy groups are expressing a mandate to Colleges of Education for the need to develop teacher candidates who "have a deeper understanding of the culture of the internal and external environments of schools" (AACTE, 2012). This is a critical issue as research suggests that teachers often do not consider race and diversity-related issues priority areas even during their training (Solomon et al., 2005). Further, teacher candidates must be prepared to skillfully apply this knowledge as they create and maintain effective learning communities.

Applying learning community theory to real-world settings supports a social-constructivist view of education wherein students learn best through a knowledge construction process that involves each and every one of them in active learning (Bielaczyc \& Collins, 1999). In response, our research explores organized opportunities for teacher candidates to partner in teaching and learning experiences with administrators, teachers, and students in urban classrooms. This article discusses how the implementation of teaching learning community propensities with TWS methodology provides a unique perspective for pre-service teachers to first examine the social context 
of urban students, and then to consider these contextual factors with the implications for effective instructional practices.

\section{Review of the Literature}

In many urban schools across the United States, learning is not a primary concern. Students live in neighborhoods riddled with crime, where they are likely to witness or be a victim of violence (Milner, 2006). Students are "often deprived of food, parental or familial support, and lack proper health care" (p. 346). This environment is not conducive to learning. In consideration of Maslow's Hierarchy of Needs (1943), individuals growing up in this environment are deficient in growth, physical and psychological welfare (Burton, 2012). Of the five levels of Maslow's Hierarchy (self-actualization, esteem, love/belonging, safety, and physiological), urban students can be lacking in any or all of the five levels. It is essential to the success of these urban students for their teachers to understand these issues, and work toward resolving them so urban schools can be filled with ready-learners.

The complex interplay of urban students' basic physical, psychological, and social needs is effectively realized in teachers building a community of learners. By connecting the theories of Maslow with the research of Putnam and Burke (2011), the classroom learning community becomes the observational setting for exploring students' learning in a social context. Haberman (2004) identified a learning community as a group that has members who "share a common vision that learning is the primary purpose for their association..." (p. 52). Bielaczyc and Collins (1999) write that, "To prepare people to live and work amid such cultural diversity, schooling needs to construct a learning environment that fosters students' abilities to work and learn with other people. Each person's contributions must be respected, and the community must synthesize diverse views" (p. 3). Students and teachers in a learning community classroom work together to achieve goals collectively, and learn to communicate effectively to achieve these goals.

Teacher Work Sample (TWS) is a performance assessment portfolio that connects pre-service teachers' classroom instruction to student performance, allowing teacher education programs the ability to monitor and coach their candidates' ability to impact student learning through instructional methods. Candidates gather pre-assessment data from students to use in planning instruction connected to state or national standards. Instruction is then customized to students' individual learning needs, which is determined through pre-assessment. Lesson instruction is followed by a post assessment that allows teacher candidates and their university faculty to analyze the effectiveness of instruction as demonstrated in the pre-post assessments. Teacher candidates then write a self-reflection that includes examples of what steps need to occur to address students who lack mastery of the material.

The TWS (Teacher Work Sample, 2014) includes seven elements:

1) Contextual Factors- What do I know about the community, district and school?

2) Learning Goals- What do I want the students to know and be able to do?

3) Assessment Plan- How will I know what students know, understand, and are able to do? How will I know if my students learn what I teach?

4) Design for Instruction- Using pre-assessment data, how will I design instruction to meet the individual academic needs of the students?

5) Instructional Decision Making- How did I facilitate student learning?

6) Analysis of Student Learning- What did my students learn?

7) Evaluation and Reflection- What conclusions can I draw from the assessment data? How will I address students who did not master the material?

Consideration of the social context using the Teacher Work Sample methodology is the catalyst for the community building process to occur. According to the Renaissance Partnership (2004):

Successful teachers make instructional decisions based on student learning rather than their own behaviors. The Teacher Work Sample (TWS) is a performance-based activity and assessment tool to help teacher candidates develop this focus on student learning. Through this performance assessment, teacher candidates provide credible evidence of their ability to facilitate student learning.

The first element of Teacher Work Sample provides a systematic framework to record the learnings and understandings gained during the process of community building. Pre-service teachers need multiple 
opportunities to carefully observe and actively listen to the students in their classrooms, in order to develop a keen sense of how to plan and deliver instruction for maximum student achievement.

\section{Methodology}

Social constructivism provides the theoretical platform for this action research. Vygotsky (1978) believed learning and development is, first and foremost, a social, collaborative experience. As such, school learning needs to occur in a meaningful context and be connected to the knowledge, understanding, and experiences students develop in the real world. Teachers, therefore, must recognize this symbiotic relationship of real-world understanding and school learning as critical to the development of the whole child.

Action research is predicated on the notion the research will improve a problem situation, address a gap or deficiency in learning, and/or enhance teaching pedagogy. In this article, the research focused on the belief that teacher education programs need to structure learning opportunities that will support success in urban classrooms (White, Brown, Viator, Byrne, \& Ricchezza, 2013). In addition, there is a social justice component present in this research. Working in inquiry communities to examine their own assumptions and develop local knowledge by posing questions and gathering data, teacher researchers also work toward social justice by using inquiry to ensure educational opportunity, access, and equity for all students (Cochran-Smith \& Lytle, 1993, 1999; Goswami \& Stillman, 1987; Meyers, Rust, \& Paul, n.d.; Stenhouse, 1985).

The classroom research involved the implementation of teaching learning community propensities in combination with Teacher Work Sample methodology. There are seven elements that comprise TWS: contextual factors, learning goals, assessment plan, design for instruction, instructional decision-making, analysis of student learning, and reflection and self-evaluation. In particular, we focus on the first element: contextual factors. Teacher candidates are required to research and then analyze the contextual factors of a district and school. Most essential to the first element is an essay written by candidates demonstrating their understanding of these contextual factors. This implications essay asks candidates to identify specific contextual factors and discuss how they would address the implications for learning, based on each factor, in their classrooms. Candidates utilize their knowledge and understanding of learning community propensities (Putnam \& Burke, 2011) as presented in their coursework and essays based on their 21 hours of field experience in Camden City, New Jersey, public elementary schools.

This implementation occurred in two sections of a 16-week, sophomore-level, initial course for pre-service teachers in the Education program at a major university. Participants $(n=52)$ in the course were informed of the unique instructional combination and planned urban elementary school experiences at the beginning of the course. Researchers clearly presented a no-penalty, opt-out selection to all participants, wherein any course member could be reassigned to another course. All course members elected to remain in the course and participate in the instructional experiences, affirming with verbal and written consents for researchers to use individual work, course assignments, and personal communications for the purpose of this study. Data was gathered and analyzed as part of the weekly routine instruction for this course, with no deviation from normal, planned course activities throughout the semester. No further intrusion on participant time or additional information outside of normal course activities was required for the study. Thus, there was no need for external approval of this study. Informal data was collected on all teacher candidates throughout the weekly course meetings in the form of observational records from class discussions and anecdotal notes from course activities. Data was also collected from each course member at the end of the 16-week course, in the form of the implications essay from TWS element one. Findings include specific excerpts from the implications essay, an examination of teacher candidates' ability to identify contextual factors in an urban setting and then apply that knowledge to enhance student learning.

\section{Data Collection and Analysis}

This experiential learning provides a foundation for sophomore-level teacher candidates at a four-year, public university to apply learning theory in urban elementary settings through field-based experiences. Based in part on the research of Responsive Classroom (2007) and Putnam and Burke's (2011) learning community propensities, in combination with Teacher Work Sample, teacher candidates develop a deep understanding of the internal and external factors of schools. In order to fully understand the social context of the learning environment, candidates first researched three aspects of the environment: 1) the community/district/school, 2) the classroom and 3) the teachers. Using this information, our candidates presented a written essay, which fully demonstrated their understanding of the implications of instruction based on these contextual factors. 
In a sense, we are practicing what we preach by modeling the stages of development in creating learning communities in our college courses. During the 16 weeks of course meetings, professors carefully created a community of learners comprised of the pre-service teachers enrolled in each course. Throughout the stages of community development, culturally responsive language is modeled and presented in think-aloud discussion sessions. As course members engaged in class discussions, professors collected anecdotal notes on post-its or notepads, using codes for each member, illuminating knowledge gained about each individual. Each week, the course professors also designed specific small group activities wherein multiple learners worked together toward a common goal. The members in these groups changed each week, allowing candidates to learn about and from a diverse set of peers. Group members engaged in sharing, problem-solving, and creative demonstrations of learned concepts, so that by doing, each pre-service teacher experiences ways of being in a community of learners.

Each researcher qualitatively analyzed the anecdotal notes written during course activities, with emerging themes or patterns identified as words and/or short phrases. These emerging themes, represented by individual participants across each course section, were recorded by date and frequency. Then, each researcher conducted a second-level analysis of the data for further reliability. Finally, themes and patterns were shared with a focus group of participants, to ensure accurate representation of participants' gained knowledge and understandings.

\section{Findings}

The academic success or failure of diverse students depends, in part, on teachers' perceptions of students and their communities (Cummins, 2000; Dei et al., 2000; Delpit, 2006).

The following excerpts, selected from three candidates' implications essays, support the deep understanding of the social context of urban students combined with the application of learning community propensities:

One implication that could keep a student from reaching their full learning potential in the classroom would be an unstable home life. This burden follows the child to school and can affect their mood and behaviors in the classroom. I would help the student by fully immersing them into the learning community so they feel part of something that is similar to that of a team and a family. Jensen (2011) talks about how important it is to build relationships among students. He stresses that student who "trust and cooperate with one another typically do better academically."

The last problem that I witnessed children in poverty bring to the classroom was the desire for constant attention. I know that a student brought up in any type of environment craves attention, but these students were different. It doesn't have to do with $A D D$ or ADHD; it is more loving and caring attention they seem to crave. The students would get to a point where they would be disruptions to the classroom. When I asked the main teachers about it, they responded that the children were like this with or without the teacher candidates present. Their behavior connects with their environment, what they head home to everyday, and their guardians. By giving the students affection, yet establishing that it is time to get to business in class will set up a positive and healthy learning community for them.

The most important thing that I learned from being in an urban classroom was that the student to teacher relationship was different than what I had expected. The problem that the fourth graders may have faced at home was unknown to me, but I observed that my cooperating teacher was a role model to her students. Since not all of her students lived in healthy homes, she had to provide necessities for them. Some educators that do not teach in urban areas may not have to provide as much as those that do teach in urban settings, but they do it because it is necessary. Putnam (2011) wrote that the function of school is to have academic outcomes, personal responsibility, social responsibility, and social justice. "Each function is a legitimate educational goal individually, but collectively they support, supplement, and substantiate each other" (p. 59), which is just what a learning community is. My solution to students understanding what a community is, to create one with help from [students].

Evelyn Ruiz, Principal of Sharp Elementary School in Camden, New Jersey, where many teacher candidates are placed for their field experience, offers her insights on the contextual factors at work in her school:

When receiving the students, I always speak to them about perceptions about our city school. I tell them that when they enter "these magic doors," they will see students who are eager to learn and teachers who value the teaching profession. I inform the students Sharp School is a special community that places a high priority on quality teaching and learning; a community where good character matters, and a community that, above all else, values its' children.

However, this is only one side of the equation. Our talented, thoughtful, and hardworking children are another reason why this community is a special one. Beyond the academic work they do in their classrooms, with the 
guidance and support of their parents and teachers, our students are learning to become responsible citizens who demonstrate the tenets of "Sharp Students" - understanding, teamwork, leadership, education, and respect (Personal communication, July 11, 2013).

Ms. Ruiz encourages children to be good students. "Helping children become life-long learners is a goal toward which we continually strive by instilling a strong desire to learn in our students" (Personal communication, July 11, 2013). Sharp Elementary School is an effective learning laboratory for teacher candidates to witness how connecting community and culture can be effective in urban areas. Teachers and students model the principles of a learning community, and as the principal of Sharp, Ruiz embodies this operational theory.

\section{Conclusion}

Relevant research demonstrates these learning communities are effective for P-12 learners as well as candidates enrolled in American teacher education programs. Teaching students the importance of and implementation of effective learning communities helps prepare them to create a successful classroom that exemplifies learning community propensities (Putnam \& Burke, 2011).

The primary outcome resulting from incorporating TWS into learning community coursework is teacher candidates gain knowledge of the social context of urban students and apply that knowledge to enhance the community of learners. Since the knowledge gained is site and context-specific, this research supports the need for more teachers to build a foundation for understanding students before they come to school. More than demographics and geography, our focus needs to be on these soft factors of who a student understands himself to be, how he interacts with others, and what part others play in learning, in essence, supporting the value of building a community of learners. Milner (2006) writes that, "Overall, the pre-service teachers who seemed most prepared and efficacious about teaching in urban schools and highly diverse settings had the most salient interactions and connections with ... cultural and racial awareness and insight, critical reflection, and the bridging of theory and practice" (p. 345).

Because social context can have a significant influence on the students' learning environment, a commitment to urban field experiences for pre-service teachers is critical to the effective application of learning theory. This urban field experience may look different in different contexts, according to various distinctions in how urban schools are represented in a specific city, region, or country. The world is not immune to the issues of poverty and the challenges of urban education that plague the American public school system. Outcomes of future research may vary due to cultural definitions and characteristics of those urban areas and urban schools under study. Educators must keep in mind the social context of students and how context affects students' success in learning. As Jensen (2009) states, “Teachers don't need to come from their students' cultures to be able to teach them, but empathy and cultural knowledge are essential" (p. 17).

\section{References}

American Association of Colleges of Teacher Education (AACTE). (2012). Retrieved May 2, 2012, from http://www.aacte.org

Bielaczyc, K., \& Collins, A. (1999). Learning communities in classrooms: A reconceptualization of educational practice. NASSP Bulletin, 83(604), 4-10. http://dx.doi.org/10.1177/019263659908360402

Burton, N. (May, 2012). Our hierarchy of needs. Retrieved from http://www.psychologytoday.com/blog/hide-and-seek/201205/our-hierarchy-needs

Cummins, J. (2000). Language, power and pedagogy: Bilingual children in the crossfire. Clevedon (UK): Multilingual Matters.

Dei, G., James, I., Karumanchery, L., James-Wilson, S., \& Zine, J. (2000). Removing the margins: The challenges and possibilities of inclusive schooling. Toronto: Canadian Scholars' Press. http://dx.doi.org/10.5860/CHOICE.38-5147

Delpit, L. (2006). Other people's children: Cultural conflict in the classroom. New York: The New Press.

Egbo, B. (2011). What should preservice teachers know about race and diversity? Exploring a critical-knowledge base for teaching in $21^{\text {st }}$ Century Canadian Classrooms. Journal of Contemporary Issues in Education, 6(2), 17-35.

Haberman, M. (May, 2004). Can star teachers create learning communities? Educational Leadership, Creating Caring Schools, 61(8), 4-10.

Jensen, E. (2009). Teaching with poverty in mind. Alexandria: ASCD. 
Milner, H. (2006). Preservice teachers' learning about cultural and racial diversity: Implications for urban education. Urban Education, 41(4), 343-375. http://dx.doi.org/10.1177/0042085906289709

Murnane, R., \& Levy, F. (1996). Teaching the new basic skills. New York: Free Press.

Nieto, S. (2000). Affirming diversity: The sociopolitical context of multicultural education (3rd ed.). New York: Longman. http://dx.doi.org/1047621950070219

Putnam, J., \& Burke, J. B. (2011). Organizing and managing classroom learning communities (3rd ed.). San Francisco, CA: McGraw-Hill.

Renaissance teacher work sample. (2013). Retrieved from http://www/wku.edu/rtws

Rimm-Kaufman, S. E., \& Chiu, Y. I. (2007). Promoting social and academic competence in the classroom: An intervention study examining the contribution of the Responsive Classroom approach. Psychology in the Schools, 44(4), 397-413. http://dx.doi.org/10.1002/pits.20231

Scardamalia, M., \& Bereiter, C. (1994). Engaging students in a knowledge society. Educational Leadership, 54(3), 6-10.

Slavin, R. (2011). Educational psychology: Theory into practice (10th ed.). Boston: Pearson.

Schalock, M. (1998). Accountability, student learning, and the preparation and licensure of teachers: Oregon's teacher work sample methodology. Journal of Personnel Evaluation in Education, 12, 269-285. http://dx.doi.org/10.1023/A:1008023412335

Schalock, M., \& Myton, D. (1988). A new paradigm for teacher licensure: Oregon's demand for evidence of success in fostering learning. Journal of Teacher Education, 39(6), 8-16. http://dx.doi.org/10.1177/002248718803900603

Teacher work sample. (2014). Retrieved from http://www.wou.edu/education/methodology.php

Vygotsky, L. S. (1978). Mind in society: The development of higher psychological processes. Cambridge, MA: Harvard University Press.

White, M., Brown, C. M., Viator, M. G., Byrne, L. B., \& Ricchezza, L. (2013). Transforming Single Story Perceptions of Urban Education: Lessons from Rowan's Urban Teacher Academy (RUTA) (In review).

Wolf, D., \& Reardon, S. (1996). Access to excellence through new forms of student assessment.

Wolf, \& Baron (Eds.). (Unknown). Performance-based student achievement: Challenges and possibilities. Ninety-fifth Yearbook of the National Society for the Study of Education, Part I. Chicago: University of Chicago Press.

\section{Copyrights}

Copyright for this article is retained by the author(s), with first publication rights granted to the journal.

This is an open-access article distributed under the terms and conditions of the Creative Commons Attribution license (http://creativecommons.org/licenses/by/3.0/). 